\title{
Death-Related Grief and Disenfranchised Identity: A Communication Approach
}

\author{
Kendyl A. Barney \\ University of Montana (USA) \\ kendyl.barney@umontana.edu
}

\author{
Stephen M. Yoshimura \\ University of Montana (USA) \\ stephen.yoshimura@umontana.edu
}

\begin{abstract}
The death of a significant person in one's life forces individuals to engage in a number of grief-related tasks, including reconstructing a narrative about the relationship, resituating their relationship with the deceased individual, and developing a new sense of self post-loss. The dominant narrative of grief, however, generally assumes that the experience is a finite, linear process of detachment. Given past research challenging the reality of that experience, we draw upon Doka's (2002) theory of disenfranchised grief to propose that grief is not only a possible temporary state of disenfranchisement, but rather a perpetual, ongoing state of being disenfranchised. This condition is primarily maintained by the need to constantly navigate the lines between the dominant narrative of grief upheld in a given culture and one's personal experience and performance of it. We propose a narrative approach to the concept of grief as a potential solution to this problem, and outline several new potential avenues for research on grief.
\end{abstract}

Suggested citation: Barney, K. A., Yoshimura, S. M. (2020). Death-Related Grief and Disenfranchised Identity: A Communication Approach. Review of Communication Research, 8, 78-95. doi: 10.12840/ISSN.2255-4165.024

Keywords: grief, bereavement, communication, death and dying, identity, narratives

Editor: Giorgio P. De Marchis (Universidad Complutense de Madrid, Spain).

Reviewers: Irwin Sandler (Arizona State University, Department of Psychology); Kara Thieleman (Arizona State University, School of Social Work); a third reviewer prefers to stay anonymous.

Received: Oct. 10 $0^{\text {th }}, 2019$ Accepted: Jan. 2020 Published: Jan. 2020 


\section{Highlights}

- The dominant narrative of grief asserts a script for the performance of grief that reinforces cultural norms into bereavement experiences.

- Grief is not merely a feeling, mental state, or passing event, but an evolving part of one's identity that involves ongoing meaning reconstruction.

- The dominant narrative disenfranchises grief experiences by assuming that grief is temporary and distal from one's identity after a significant loss.

- Doka's (2002) theory of disenfranchised grief is extended to suggest that disenfranchisement occurs in degrees, rather than in particular circumstances.

- Narrative methodology can illuminate aspects of grief identity in the context of a dominant narrative that might otherwise be invisible.

- Future research could examine cultural dimensions of disenfranchisement, and explore ways in which social interactions potentially increase or decrease disenfranchisement.

\section{Content}

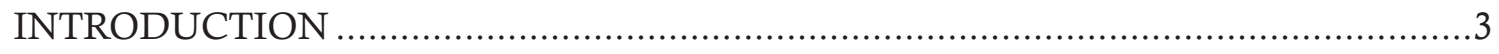

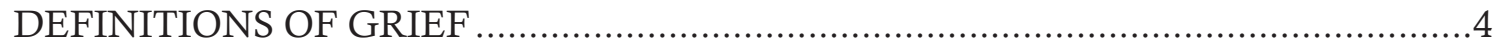

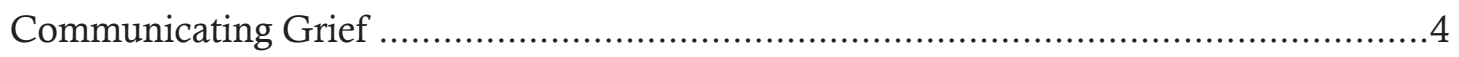

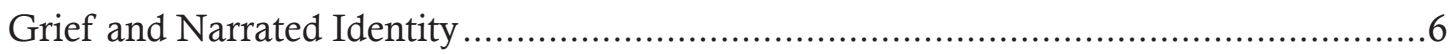

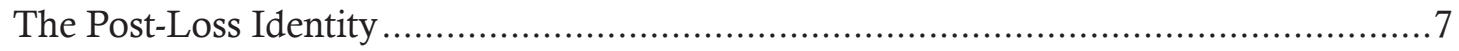

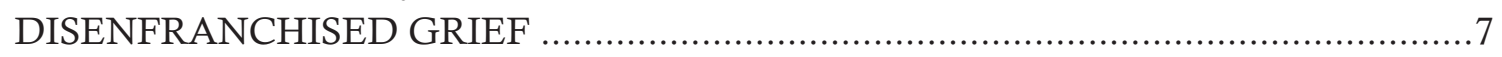

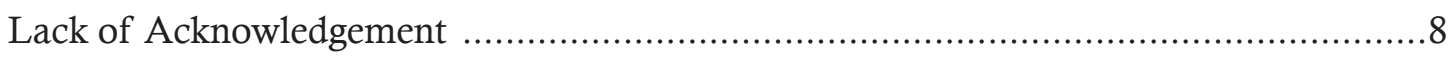

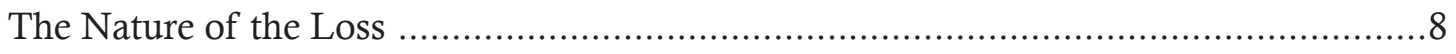

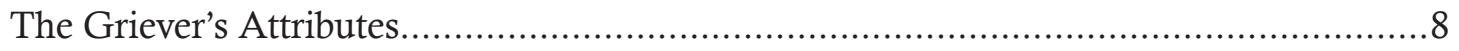

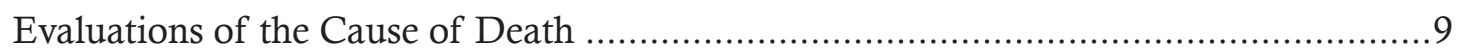

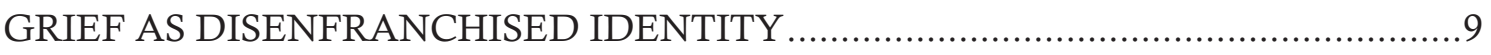

The Role of Communication in Disenfranchised Grief Identity ................................ 10

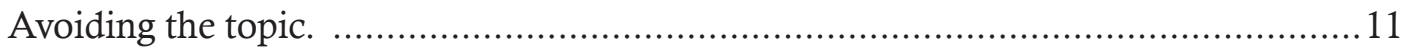

Displaying of over-sympathetic emotions. ....................................................... 11

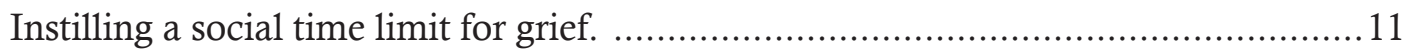

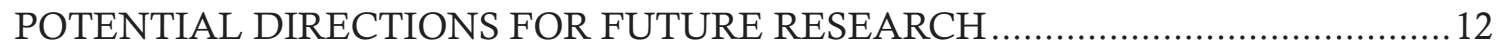

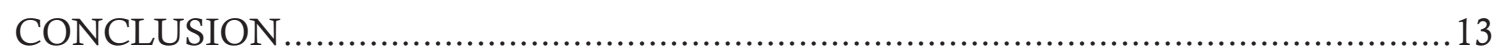

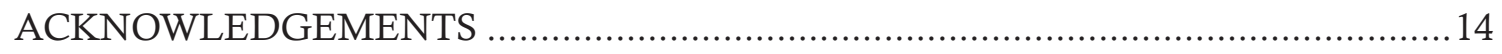

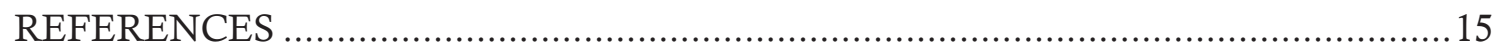


Grief is among the most complicated personal and social experiences people can have. Those who have lost a close relationship partner commonly report a deep sense of isolation stemming from the loss of the physical presence of the loved individual (Goodrum, 2008; Ironside, 1997). Yet, the perceived isolation that follows a loss can also coexist with a strong sense of a continued, committed relationship with the person they have lost - an individual with whom they can no longer interact and maintain the relationship in traditionally communicative ways (Barney, 2019a). Communicating this experience can be challenging not only because the situation itself can be psychologically turbulent, but also because communicating about the experience with others would require one to share a vulnerable and intimate part of oneself. Grieving individuals might not believe others necessarily have a claim to knowledge about such private aspects of their lives, and others might not even want or know how to respond to the disclosure of such a private experience.

The difficulty of expressing grief further stems from the fact that people often grieve in the context of a "dominant narrative of grief." This dominant narrative adheres to an ideal image of "normal" bereavement performance (Neimeyer, Klass, \& Dennis, 2014). In many cultures, this narrative typically involves a process of detaching from the deceased, working through the grief in a certain amount of time, and abiding by social norms around the expression of the experience. However, cultural norms do not often align with the actual experience of grief. Consequently, the enactment of grief can vary by intensity and behavior across time as bereaved individuals continually try to align their experiences and expressions with the socio-cultural expectations of "proper" or "normal" grieving. As the display of grief-related emotions is constantly subject to cultural display rules (Neiemyer et al., 2014), grieving individuals navigate a social arena in which they might feel inclined to express emotions in ways that do not fit with a given performative ideal around the experience of grief, while also knowing that doing so can result in social sanctioning. Such an experience can hinder honest communication about the experience, promoting a sense of isolation even in the midst of deep connection with other relationship partners.

The dominant narrative of grief easily proliferates among individuals who have never experienced the death of a significant person, partly because the experience is perplexing and difficult to explain by those who have had such experiences (Jakoby, 2014; Ironside, 1997; McInerny, 2018a). Because non-bereaved counterparts might wish to be polite, or at least not hurt or offend a bereaved individual, they might choose to avoid the subject altogether, believing that asking about the deceased individual will upset the bereaved person (Basinger, Wehrman, \& McAninch, 2016; Goodrum, 2008; Walter, 1996). Popular media and outdated grief theory can further perpetuate the misconception that grieving is a step-by-step process that one can "get over" in time, and that thoughts about the deceased become obsolete or unnatural after a certain point (Buglass, 2010; Granek, 2010; Kofod, 2017). Bereaved individuals can consequently come to feel isolated from their social network members, because those people may be uncertain how to approach and support the grieving individual, unknowledgeable about the experience of grief, or inaccurate in their beliefs about what exactly the grieving person is experiencing.

Thus, grief is disenfranchising, by which we mean that grieving individuals easily have their feelings discredited or overlooked and lose opportunities for social support because of a discrepancy between the dominant narrative of grief and the actual experience of it. Grieving individuals might feel pressure to confine their grief performances to expressions that fit within the dominant narrative, or they simply grieve in isolation because the experience cannot easily be openly articulated when it inevitably deviates from the dominant narrative.

In this essay, we draw upon Doka's (2002) theory of disenfranchised grief to argue that grief, by its continuous, reoccurring, and performative nature is not just disenfranchised in some circumstances, but is rather perpetually disenfranchised. We posit that grief is not just a temporary experience, but actually becomes a core aspect of one's identity. We conclude that grief, as a communicative action, can be a pathway by which people negotiate this aspect of their identity and open doors to validation, understanding, and caring. Notably, not all grief will unfold in the same way, and not everyone will recognize their own grief experiences as disenfranchised. Thus, grief might be experienced to different degrees, depending on how sensitive an individual is to the discrepancy between one's own experience and the dominant narrative, and the extent to which one's own narrated identity differs from the expectations set forth by others in one's own social context.

The purpose of this essay is to offer a conceptualization of grief as a perpetually disenfranchised experience, and 
explain this experience as a function of the discrepancy between one's understandings of their own experiences and the larger understandings upheld by the dominant narrative of grief. We begin our review by elaborating on the conceptualization of grief and discuss the communicative approach we take to the concept in this essay. Working from the position that grief is a social phenomenon, we discuss the narrative aspects of grief and the intersection between narratives and one's identity, ultimately arguing that grief and identity are integrated through the process of narrating. We propose that narratives can help resolve discrepancies between one's grief experiences and the overarching dominant narrative by allowing individuals to retell their story about both their relationship with deceased individual and their new identity. Thus, the communication (narration) of bereaved identity can help manage the ongoing disenfranchisement that stems from the discrepancies between one's lived experience and the dominant narrative of how one is "supposed to" grieve.

\section{Definitions of Grief}

For the purposes of this review, we utilize Buglass' (2010) conceptualization of grief as "a natural human response to separation, bereavement or loss ... describ[ing] an individual's personal response to loss and [having] emotional, physical, behavioral, cognitive, social and spiritual dimensions" (p. 44). Noting the distinction between grief as a response to the condition of loss itself, we define bereavement as the condition of deprivation following the loss of a loved one through death (i.e., Dennis \& Kunkel, 2012). We thus analyze grief as one's response to being bereft of a loved one after their death, whereby survivors are forced to reconstruct meaning of the loss, resituate their relationship with the deceased loved one, and learn how to continue with old and new roles in their day-to-day life.

In this conceptualization of grief, emotional reactions are not the only ways in which grief can manifest itself; they can also present in the form of cognitive, spiritual, social, or action-oriented reactions (Corr, 1998; Doka \& Martin, 1998). For example, grief can be experienced cognitively by way of difficulty concentrating, hallucinatory experiences, depersonalization, idealizing the lost person, dreams/sleep disturbances, and loss of appetite (Doka \& Martin, 1998). The enactment of such experiences involves a behavioral component that may be completely separate from any emotional expressions one might perform.

The manifestations of grief can recur for long periods of time. For instance, following the death of a family member, holidays might include moments of mourning even decades later because they may have historically been associated with familial bonding and togetherness. Such realities stand in contrast to traditionally held theories of "grief work" (Freud, 1917/1957) and stage theories (e.g., The 5 Stages of Loss; Kübler-Ross \& Kessler, 2005), which uphold a more finite, linear perspective on the process. Thus, recent grief scholarship suggests that grief ought to be understood in more nuanced and multifaceted terms than stage theories allow (Neimeyer, 2014; Spaten, Byrialsen, \& Langdridge, 2011). Current theoretical approaches to grief, such as continuing bonds theory (Klass, Silverman, \& Nickman, 1996) and the dual-process model (DPM; Stroebe \& Schut, 1999) highlight the ways in which grieving is cyclical, orderless, and recurring in nature. We further elaborate on these ideas in the following sections.

\section{Communicating Grief}

Despite the common conceptualization of grief as a private, internal experience alone, several reasons exist to believe that grief can be a social, communicative phenomenon. First, grief is inherently a social experience, stemming from the loss of a relationship partner, and prompting individuals to begin interacting with others in purposeful ways. Scholars suggest that grief can serve a number of social functions and be subject to emotional regulation for the purpose of maximizing the effect of those social functions (Archer, 2008). From this approach, negative reactions to separation from attachment figures are a normal response, probably an evolved adaptive mechanism used to alert social animals to the need to reunite with their attachment figures (Bowlby, 1980). Likewise, grief can be conceptualized as part of a larger repertoire of reactions to separation, perhaps a spurious adaptation of the attachment mechanism designed to motivate us to maintain close bonds that could play a role in increasing inclusive fitness (Archer, 2008). Humans have many simultaneous social goals in the process of interacting with others (Dillard, 1990), and while they may not be able to control the experience of emotions, they can and do attempt to regulate their emotional expressions because the quality of their interpersonal relationships depends on doing so (Lopes, Salovey, Côté, \& Beers, 2005). 
The second reason to believe that grief is a communicative activity is that the link between loss, grief, and one's sense of self is connected by way of the narratives that people create and share about the loss. Grief can manifest itself in an array of coping responses and communicated messages (Bonanno, 2001), partly because it is a longer-lasting affective experience than are transitory emotional experiences such as mere sadness. Moreover, grief is intertwined with one's identity and the loss that has become part of it. In other words, grief is not merely a feeling or cognitive event, but is rather an evolving, ongoing personal narrative and affective experience (Goldie, 2011).

The diversity of responses to grief over long periods of time can give way to the development and narration of largescale, encompassing stories about the nature of the loss. As Neimeyer, Klass, and Dennis (2014) write, for example:

Our sense of self is established through the stories that we tell about our lives, the stories that others tell about us, and the stories that we enact in their presence. It is this self-narrative that can be profoundly shaken by the 'seismic' life events such as the death of a loved one and ... narrating grief instigates the processes of reaffirmation, repair, or replacement of the basic plot and theme of the life story of the bereaved. (p. 489)

Neimeyer et al. essentially argue that identity following loss is constructed through stories, suggesting a communicative component to both identity construction and one's associated narrative. To experience a loss is to experience a change in identity, but that shift occurs in the process of developing - and telling - the longer-term narratives about the loss itself.

Third, bereavement is an interpretive experience, and the meaning-making process is both psychological and interactive (Neimeyer et al., 2014). As with many adverse circumstances, these meanings may include global meanings (i.e., individuals' general orientations to beliefs, goals, and broad views surrounding justice, control, predictability, etc.) and situational meanings (i.e., meaning in the context of a specific event; Park, 2010). Just as emotions may be instigated via appraisals and meanings developed around social situations (Lazarus, 1991), so too is grief developed by way of meanings constructed around the loss of a significant person in one's life.

The meanings associated with the life and death of the deceased are created through social interaction between surviving family members and friends. Taking a biographical approach to grief, for example, Walter (1996) explains that collectively mourning a deceased friend with others helped provide a "stable place" for this lost friend among the survivors. For Walter, grief was not a "matter, as the bereavement literature so often portrays, of friends 'supporting' the bereaved but of a number of bereaved persons working out together who Corina [the deceased] was and what she meant to them" (p. 13). Of course, grief also involves many other communicative acts, such as attending ritual ceremonies, receiving and providing enacted social support (e.g., grief support groups), or becoming further involved in religious communities and activities. The diverse content that grief performances can carry both reflects and enables the construction of meanings around grief by reflecting the variety of scripts that cultures adapt and promote. Yet, the variety of ways in which grief is performed can also provide the means by which grief-related messages and the intended meanings behind them can be made more clear to others.

Finally, grief and the related state of bereavement involve the seeking of, reception to, or further lending of social support, which is the "interpersonal transaction involving one or more of the following: (1) emotional concern (liking, love, empathy), (2) instrumental aid (goods or services), (3) information (about the environment), or (4) appraisal information relevant to self-evaluation" (House, 1981, p. 39). Following the death of a loved one, families often receive significant amounts of support from their community in the form of kind words, sympathy cards, flowers, meals, and memorial services. Many bereaved individuals seek out social support in the form of grief support groups through community organizations, college campuses, and religious communities. Additionally, some grieving individuals go on to help others who are bereaved within these support groups or within their interpersonal relationships. Such acts carry message-value about the amount and quality of functional and structural support that a grieving individual can access. Perhaps this is why "talking about grief is considered to be one of the most helpful remedies in the case of bereavement" (Jakoby, 2014, p. 13).

Certainly, not all grief will be displayed in the presence of others. Just as cultural display rules sometimes dictate that anger, sadness, or even elation should be expressed through silence and avoidance, so too might grief be modified in performance to accomplish the myriad of social goals that one might have at any given time. Indeed, the whole point of regulating the emotional experience of grief would be to maximize the social functions of the emotional 
experience itself, including obtaining further support and minimizing the experience of loneliness or social isolation (Fischer \& Manstead, 2016). In some cases, withholding grief expressions could be the best way to achieve this or other personal and social goals.

The dominant narrative of grief prescribes the social norms and cultural rules of how one should grieve appropriately: not too much, but not too little (Moran, 2016). This narrative provides a script for the performance of grief by reflecting and reinforcing cultural norms of death and grief into the experiences of individuals affected by loss. As Neimeyer et al. (2014) put it, "individuals are subjected to and sometimes subjugated by a dominant narrative of grief, which constructs their identity as bereaved people, and which regulates their proper performance of their role as mourners..." (p. 493). The contention that bereaved individuals are both subjected to and subjugated by the dominant narrative of grief suggests that a proper way of grieving, or a "script" for expressing (or not expressing) grief, exists. For example, families, organizations, and cultures may either implicitly or explicitly assert expectations about the particular times, places, ways, and degrees to which the loss is communicated when one is "properly" grieving. The asserted expectations serve as the script, and the script is modeled and reinforced when people reflexively perform grief alongside these expectations over time. Stigmatization follows when people are not be able or willing to follow a given scripted process for grief, partly as a way of reinforcing the importance of the script.

\section{Grief and Narrated Identity}

When a family member dies, members of that family are instantly confronted with identity-related questions about who they are in relation to others and as individuals (e.g., "who am I now" or "what is my family") without the person in their life (Baddeley \& Singer, 2010). In that way, loss poses an immediate challenge to one's previously established sense of self. The forever unfinished nature of this experience makes grief an ongoing project of identity negotiation.

Narratives offer a potential solution to this problem. By developing and telling narratives, individuals weave the biological, psychological, and social dimensions of human life together into a "coherent sense of self that provides continuity across past experience and meaning and purpose for future endeavors" (Baddeley \& Singer, 2010, p. 199). Thus, the narratives people construct during changing social situations help form and manage one's sense of self (Burke, 1980; Stryker, 1980).

For many people, meaning and identity are formed at least partially through constructing evolving narratives (McAdams, 2001). As Greenberg and Rubin (2003) suggest, "storying" events consolidates them into larger autobiographical memories that are reconstructed over time. Koenig Kellas (2018) likewise suggests that the stories we hear and tell affect our actions, self-concept, and well-being. Some tentative evidence supports this connection between grief and narrative construction even at the neurophysiological level. For example, Gündel, O'Connor, Littrell, Fort, and Lane (2003) obtained magnetic resonance images of grieving participants' brains while they were presented with pictures of their loved ones along with words taken from their own narratives of the loss (e.g., "cancer"). As Neimeyer et al. (2014) report, participants in this study showed heightened activation around the seats of autobiographical memory and emotion during this condition. They suggest that grief appears to be experienced like many other emotions, around the interpretations, appraisal, and meanings that people make about their social experiences.

However, the process of explaining loss by death and constructing meaning around it can be complicated by the fact that death and grief are an anomie, or "a strong sense of normlessness, an uncomfortable feeling of uncertainty that can add to distress" (Thompson et al., 2016, p. 176). The anomie can give way to meanings and explanations comprised of self-defining memories, which are "vivid, emotionally intense, repetitively recalled, linked to similar experiences, and organised around an ongoing concern or unresolved conflict with the individual personality" (Baddeley \& Singer, 2010, p. 200). Park (2010) also claims that meaning-making involves identity reconstruction by shifting one's biographical narrative as a result of experience. While self-defining experiences will indeed disrupt one's current, ongoing narrative identity, they can also play an important role in grief management as they promote narrative formation and help people develop a new sense of self in the midst of grieving their loss (Baddeley \& Singer, 2010; Neimeyer et al., 2014). Narratives help grieving individuals by allowing them to: (a) integrate multiple perspectives about the situation, (b) evaluate events, (c) place those events into a larger context, and (d) ultimately reconstruct and resituate their identities and experiences within their life's narrative 
(Goldie, 2011). We would add that the mere formation of the narrative in one's mind is just one part of the narrative process. The actual telling of it to others is also crucial.

Indeed, grief theorists suggest that narrative formation and meaning-construction are negotiated between and among people through the process of communication (Goldie, 2011; Neimeyer et al., 2014; Stroebe, 2010; Walter, 1996). Neimeyer et al. (2014), in particular, posit a model of mourning in which meanings around the loss are socially constructed via the process of interaction and narration with others, both about one's bereavement and about the deceased (Walter, 1996). Research supports this idea. For example, Willer et al. (2018) invited surviving children and adolescent family members to create loss-remembrance drawings following the death of an infant in the family. The researchers concluded that drawings portrayed three main themes: narration of individual and relational identity, narration of the life and death of the baby, and narration of growing sensemaking. Relevant to our current argument, few of the drawings focused on the dominant narrative of devastating loss, but rather tended to portray the ongoing lives of themselves, their families, and even the babies. This finding seems to imply that grief is an ever-evolving part of one's life, and subject to integration into one's sense of self via the narratives that people construct around the loss.

\section{The Post-Loss Identity}

Grieving individuals' identities are unlikely to completely return their pre-bereaved state, partly because of the ongoing nature of post-loss narrative formation. Instead, the loss, grief, and narrative become integrated as key components of one's identity moving forward. For example, Phipps (2018) writes:

Time has elapsed, and I have been able to reflect on who I am, now. I have grappled with this: Are the changes I have experienced as a result of this trauma changes to my identity? I am no longer a wife, or a Police spouse. I am many things, but I am no longer either of those things. This year, 2018, we would have been married for 12 years and together for 18. I've been "wifey" for a good proportion of my existence. That has gone. New nouns have entered the dialogue, such as widow. Widowhood. That is a collective identity that I'm grappling to accept membership within (p. 7).
Yet, while a label exists for someone who has experienced the loss of a spouse, curiously few labels for other losses exist. For instance, while Phipps has a term to draw upon to describe the change in her identity from "wifey" to "widow," she has fewer clear terms to invoke to describe the changes in her identity to "solo mother" and "ex-police wife." She states, "I recognize that parts of my overall identity have changed along with the generation of new understandings that have come as a result of the trauma I have been through" (p. 8).

Likewise, in a study of sibling-loss, Funk, Jenkins, Astroth, Braswell, and Kerber (2018) found that the loss of a sibling changed participants' identity via their new role in the family and the terms they used to describe that role, such as the number of siblings they had, their birth order, and the differences in ages. As Funk et al. highlight, siblings expressed sadness, frustration, and confusion regarding the shifting of birth order and placement of the surviving siblings, especially if they then became the oldest or only child. The narratives illustrate not only how identity and family are forever changed following the loss of a sibling, but also how the roles and labels used to describe one's identity also change, bearing weight on the question, "who am I?"

In short, the formation of a new identity in the midst of grief and the challenge of describing one's identity following loss by death presents a grieving individual with a vexing problem: how does one have a new identity acknowledged by others, when the cultural norms surrounding the expectations around the performance of grief and death are different from how one feels the experience must be expressed? This experience gives rise to the possibility that grief is disenfranchised as part of one's identity.

\section{Disenfranchised Grief}

Disenfranchised grief is a condition of grief "experienced when a loss cannot be openly acknowledged, socially sanctioned, or publicly mourned" (Doka, 2002, p. 160). Those whose grief is disenfranchised may have their feelings discredited or overlooked, not be provided socio-emotional support, or may feel pressure to confine their grief to solidarity. Doka (2002) argues that the existence of disenfranchised grief acknowledges that every society has a dominant narrative of grief. In the presence of the dominant narrative, grieving people sometimes disenfranchise themselves by 
refusing to share the loss out of fear, shame, or blame (Kauffman, 2002). Whether the cause of disenfranchised grief is interpersonal or intrapsychic, grief is easily left unacknowledged and unsupported, leaving one to feel potentially "alienated" in their experience (Thompson et al., 2016). Doka (2009) argues that disenfranchised grief occurs for a variety of reasons, including lack of acknowledgment, the nature of the loss, the griever's attributes, evaluations of the cause of death, and lack of validation for the way an individual grieves.

\section{Lack of Acknowledgement}

A variety of reasons exist for why a loss may not be acknowledged, but one of those reasons is because the relationship shared with the person defies accepted heteronormative ideals of relationships (e.g., extra-marital relationships, interethnic, or same-sex relationships). Because the relationship itself might lack social validation, grieving individuals can become disenfranchised via the inability to have their articulations of grief likewise validated. For example, queer relationships have historically been "invisible, eliciting disapproval, discrimination, and physical violence when revealed" (Green \& Grant, 2008, p. 279), and same-sex couples were unable to legalize their relationship through marriage until 2015. Even so, same-sex relationships continue to face stigmatization, scrutiny, and invalidation. When one of the individuals within the partnership dies, the survivor's grief risks being disenfranchised by others, and seen as less significant than heterosexual widowhood.

\section{The Nature of the Loss}

In some cases, a loss might not be recognized as an actual loss of a life, such as in perinatal deaths (e.g., miscarriage, stillbirth, or abortion), or 'social' or 'psychological deaths' (e.g., those who are institutionalized, comatose, or lacking consciousness of existence, as in being 'brain dead'; Doka, 2009). Lang, Fleiszer, Duhamel, Sword, Gilbert, and Corsini-Munt (2011) suggest that the nature of perinatal loss encourages public disenfranchisement of perinatal grief because it is relatively ambiguous ("stemming from the concurrent physical absence of and psychological presence of the fetus or infant;" p. 184). However, perinatal loss also contradicts traditional understandings of and hopes for pregnancy and childbirth, thus defying the dominant narratives of grief, death, and child-rearing. The consequential feelings of disenfranchisement impede bereaved parents' psychological well-being, hinder coping, and strain marital and familial relationships).

While disenfranchisement of perinatal grief is significant for both the mother and father, Bonnette and Broom (2011) point out that fathers can experience unexpectedly high disenfranchisement in grief. While perinatal deaths are obviously significant for women (including greater physical involvement and potentially significant pain and medical attention), men can feel their grief is oversimplified by comparison. Indeed, men in many western cultures are typically held to a hegemonic masculine ideal of strength, which often results in inexpressiveness, stoicism, and/or rationality in most contexts. Grief is no exception, and the expectations around grief performances by men are further indicative of the dominant narrative surrounding grief and its expressions.

Doka and Martin (1998) point out that men (and many women) express grief in ways that are more instrumental, action-oriented, and inwardly reflective rather than emotionally expressive. This finding is consistent throughout studies on grief and gender (Creighton, Oliffe, Butterwick, \& Saewyc, 2013; Doka \& Martin, 1998). While "outpourings of emotion do not necessarily foster a 'better' experience of grief" (Creighton, et al., 2013, p. 42), others may see inexpressiveness as absence of grief; thus, leaving deep experiences of mourning unacknowledged. Conversely, a grieving individual perceived as grieving "too much" or for "too long" could also meet stigmatization. Although grief can be disenfranchised for everyone, the ways in which it is performed can scale the degrees to which people experience grief as disenfranchised.

\section{The Griever's Attributes}

Grief might also not get recognized because of a perceived lack of involvement, awareness, or cognitive ability on the griever's part. For example, both children and elderly adults are often perceived to have little ability to comprehend the death of a significant person (Doka, 2009). In the case of children, the dominant narrative might hold that they are too young to understand the situation, and perhaps oblivious to its significance and in need of protection via topic avoidance. In the case of older adults, the loss of a partner might be considered normative and expectable, and thus not in 
need of much discussion (Kusmaul \& Anderson, 2018). A1ternatively, older adults who experience symptoms of cognitive decline might be treated similarly to children, and "protected" by others by way of topic or physical avoidance. These individuals are often deprived of knowledge during end-of-life and left out of ritual processes such as organizing or attending memorial services (Doka, 2002).

However, such narratives fail to acknowledge the reality that both younger and older individuals are equally capable of experiencing grief. Perhaps such people are disenfranchised because their demographic or cognitive attributes do not fit into the dominant narrative's model of the typical "griever." Yet, another possibility is that their performance of grief does not fit within the dominant narrative, and is thus discounted or invalidated as grief itself. In fact, a variety of grief studies suggest that individuals affected by grief feel uncomfortable discussing their experience when it does not match the dominant narrative of grief (Doka, 2002; Doka, 2009; Goodrum, 2008; Ironside, 1997; Neimeyer et al., 2014; Thompson et al., 2016). As Jakoby (2014) notes, "modern society constrains the possibilities of talking about the dead" (p. 14). As such, disenfranchisement can be enhanced for three possible reasons. Either: (a) people do not recognize a griever's ability to experience the loss, (b) grievers may not feel comfortable expressing their grief in traditional ways, or (c) their actual expressions of grief are not recognized as such by others.

\section{Evaluations of the Cause of Death}

Just as societies may have normative expectations about what constitutes appropriate or normal grieving behaviors, cultures also develop values around the notion of "bad" and "good" causes of death. To the extent that these values become part of the dominant narrative, they too can delegitimize or even stigmatize bereavement. Van der Geest (2004) argues that assigning such evaluative labels to causes of death often hinges on the degree to which the death is "seen as a voluntary or non-voluntary matter" (p. 884). Whereas good deaths align with the dominant narrative, bad deaths defy it. Drug-related deaths, suicide, death from AIDS, and homicide, just for example, are often socially censured and can result in both disenfranchisement and stigmatization among family members who grieve those types of causes. As Valentine, Bauld, and Walter (2016) write, "those who are grieving so-called self-inflicted deaths can be obscured by commonly held assumptions and stereotypes. These may devalue or 'disenfranchise' their grief, depriving them of the opportunity to share their experiences with others and, therefore, of social support" (p. 286). Other studies have likewise found that deaths by perceivably self-inflicted causes are often blamed, shamed, and stigmatized and the grievers subject to exclusionary treatment (Feigelman, Jordan, and Gorman, 2011; Pitman, Stevenson, Osborn, \& King, 2018). As both cause and consequence of disenfranchisement, families sometimes feel a need to protect their child's reputation by misrepresenting the cause of death to others (Valentine et al., 2016; Pitman et al., 2018). Naturally, the disenfranchisement and stigmatization of these causes can result in distress and further sense of isolation.

Doka's model further highlights the fact that grief and death are subject to cultural norms. Notably, the theory posits that individuals, communities, and societies tend to disenfranchise certain grief experiences by not acknowledging the relationship, the loss, the griever, the cause of death, or even the way in which grief is expressed, because individual narratives of grief and the performance of grief identity run counter to the dominant narrative within a given culture. However, the idea that disenfranchisement occurs in only particular circumstances overlooks the possibility that grief by itself, regardless of circumstance, often contradicts the dominant narrative wherein grief has a starting point, linear progression, and eventual ending point. Given that grief does not always follow this pattern and can be conceptualized as an aspect of one's identity, however, an approach that conceptualizes grief as persistently disenfranchised and communicated as part of one's identity would be appropriate. Such an approach may help to determine competent ways of moving through the experience, however long it may last, and in whatever forms it may take.

\section{Grief as Disenfranchised Identity}

As previously discussed, the dominant narrative assumes that one can and should desire to a return to pre-bereaved state of being following a loss. This narrative, however, asserts an unrealistic expectation for how people should grieve, given that part of what might be grieved is not just the loss of a person, but in fact the loss of a way of life (Rosenblatt, 1996). The experience of grief is ongoing, constantly changing, and unlikely to have recognizable end-states that fit well 
with the dominant narrative. Essentially, loss disrupts biographical narratives and in turn requires reconstruction of meaning during grief (Neimeyer et al., 2014; Park, 2010; Walter, 1996). Just as the experience of grief is ongoing, so too is the meaning-making process while individuals and families adapt to life after loss by developing new roles, new rituals, and new ways of relating.

Doka's original theory of disenfranchised grief assumes disenfranchisement is highly contextual. However, the dominant narrative of grief ignores the contextual aspects of grief, and thereby disenfranchises all grief experiences by supposing that grief is separate from one's identity after the death of a significant person. In other words, the dominant narrative of grief is disenfranchising by assuming that grief is linear and a temporary state of being, external to one's sense of self. In the absence of a conceptualization of grief that allows for grief to actually become an ongoing part of an individual's identity, one could conclude that grief would be perpetually disenfranchised.

By its nature, disenfranchisement can occur in degrees: individuals may certainly feel their grief as disenfranchised to greater severity based on the tenets of Doka's original theory. Similarly, drawing from Bonanno et al.'s (2002) and Bonanno, Boerner, and Wortman's (2008) research on grief trajectories, individuals may feel a lesser or greater sense of disenfranchisement based on their reactions to grief, as related to social functioning and adjustment. However, even those who experience grief after a socially acceptable and acknowledged death and those who exhibit behaviors of high functioning and resilience can experience disenfranchisement over time. When the dominant narrative maintains a set of "acceptable" conditions and ways of grieving that have only a passing connection to the realities of the experience and expression of it, a vicious cycle exists wherein grieving individuals are constrained to perform grief within the parameters of a dominant narrative that often has little to do with their modes of intentional and unintentional expression. Failure to fit into the dominant parameters results in further disenfranchisement, which potentially drives further divergent modes of expression.

\section{The Role of Communication in} Disenfranchised Grief Identity

Grief literature offers numerous practical suggestions for communicating about grief, but the performance of grief is easier spoken about than actually done. As Jakoby (2014) points out, "there is a discrepancy between the scientific notion of the importance of talking about grief as the practical guidelines on the one hand, and the everyday reality of bereaved people, who have to deal with various difficulties of communicating grief, on the other" (p. 13). It is within this discrepancy that disenfranchisement of grief exists.

Disenfranchisement is further woven into the performance of grief because the dominant narrative about grief's nature and process exerts pressure on the performance itself. In an effort to maintain a sense of competency, grieving individuals must conform to social expectations of grieving in performing their experiences, even though they might not be motivated to do so. The clash between the dominant narrative of grief and the actual experience of it exemplifies the discrepancies between one's global meanings and situational meanings about grief and death (Park 2010), and this discrepancy helps explain the distress that likely follows. As Park (2010) puts it, "the extent of discrepancy between the appraised meaning of the event and the individual's global meaning is thought to determine the level of distress experienced" (p. 259). Even as one attempts to align their performance of grief with cultural norms, the individual can come to feel increasingly isolated, misunderstood, or disenfranchised as a function of the mismatch between their experience and the social expectations they live within.

Funk et al. (2018) show several examples of this problem in their interview study on grieving siblings about their disenfranchisement experiences at school. One participant in the study stated, "when you tell someone you lost your brother, they say, 'Boy that must have been horrible on your parents.' ... (But) this is a kid that I was with every day of my life ... This was my best friend" (p. 9). In this example, the respondent's grief was disenfranchised by having their grief discredited as less significant than the parents' grief. Grief can also be disenfranchised through statements such as, "at least they aren't suffering anymore," or "at least they are in a better place." In these cases, grief is diminished by focusing the conversation on the death rather than the loss. Grief can also be blatantly discredited through remarks such as "It's time to move on" or "You should be over this by now." However well-intentioned, such comments are both fueled by, and further perpetuate the dominant narrative of grief that individuals grieve temporarily and appropriately, thus disenfranchising the grief that is a continuous part of one's identity. 
In many cases, the dominant narrative of grief is unintentionally imposed on bereaved individuals, as interlocutors simply do not know what to say (Basinger, et al., 2016; Walter, 1996; Walter, Ford, Templeton, Valentine, \& Velleman, 2017). However, non-bereaved counterparts can still signal discomfort with (or disapproval of) expressions of grief in at least three ways: by avoiding the topic, displaying oversympathetic responses (e.g., crying), or pressing a social time limit for grieving (Goodrum, 2008). As one might infer, these are also likely to be three ways of performing the dominant narrative that can perpetuate disenfranchisement.

\section{Avoiding the topic.}

Performances of non-bereaved counterparts might involve avoiding performance altogether. Goodrum (2008) suggests that "avoidance allows people to minimize the likelihood that they will see and then share the victim's pain" (p. 430). Avoidance is not exclusively a choice of outside individuals, however; grieving persons often make this choice as well. In a study exploring disclosure and avoidance in grief communication (Cohen \& Samp, 2018), for example, a participant who lost her pregnant mother in a car accident, offered some reflections:

I never talked about it [the death] with anyone except my dad, and he's been great. My friends knew my mom died, but that's it. I mean, what would people say about the girl with no mom, the girl whose mom died carrying her baby brother? (p. 247)

In the same study, respondents reported performing through role-model enactment, which is defined as "becoming someone else who is capable of" coping with the problem that one faces (Sharoff, 2004, p. 59, as cited in Cohen \& Samp, 2018). For example, one respondent spoke of her role-model enactment at her great-grandmother's wake:

When my grandpa died, my dad was the one who handled everything. I'd see him smiling and greeting and welcoming random people at the wake. I didn't like all these people I didn't know showing up, but I felt like I had to put on a mask for them because it seemed like my dad did. Well, when my great-grandmother died, I was told that I was an adult, and I needed to do what needs to be done. I still don't really think 18 is being an adult, but I just tried to remember what my dad did when my grandpa died ... Being told that essentially it's okay to put on a mask for people just forced me to ignore my feelings. And then I just never talked about it. (p. 250)

Clearly, even silence can have message value (Johannsen, 1974). When individuals avoid the topic, they communicate information about either what they believe is expected from them, or about who they are or want to be as individuals, or in relation to others. The young woman who performs grief by avoiding the topic might be trying to send signals to others that she is "an adult," and a responsible participant in her family.

\section{Displaying of over-sympathetic emotions.}

Performances of non-grieving counterparts sometimes involve melodramatic reactions that distract from the grief of the individual who experienced the significant loss. Such reactions can serve as solicitations from the non-grieving partner for their own support, and serve as messages about their expectations about the bereaved person's identity. This type of reaction, however, also carries potential for disenfranchisement of the grieving individual. As the stepmother of a murder victim stated, “...at that point they're dealing with their own upsetness. They need to get their own upsetness [out]. You can't be there for somebody else if you are dealing with your own upsetness" (Goodrum, 2008, p. 431). In essence, over-sympathetic displays of emotion contribute to disenfranchisement by positioning the grieving individual as a supporter rather than the person in need of support, and by disregarding the grieving individual's newfound aspects of identity in grief.

\section{Instilling a social time limit for grief.}

As previously discussed, performances of non-bereaved counterparts might include statements that attempt to conform grieving individuals' narratives to social expectations of grief. A theme widely reported in studies are misconceptions about grief's timeline, exhibited in statements resembling "It's time to move on," (Dennis \& Kunkel, 2012; Goodrum, 2008; Ironside, 1997). In Goodrum's (2008) study, one mother of a murder victim recounted times she had heard similar statements from others: "That's the main thing people will say. It's like [they'll say], 'Hey, you ought to be over this.' It's like, how do you know? And that's how I feel about it. When they can be like, 'You should be over this.' It's like, you don't have a clue as to what I'm going through" (p. 432).

Ironside (2018) likewise comments that people are "quick to ram their own ideas of what they like to think of as the 
'grieving process' down your throat" (p. 123). She notes that those around grieving individuals can get impatient. In her experience, friends saw her as "stuck in depression" following her loss, when, in reality, she was living the experience as it was: "reacting to some kind of force over which I had no control" (p. 80).

The examples provided highlight how the dominant narrative of grief disenfranchises individuals' grief experiences and associated identities. The uncertain nature of grief is both a product of, and additional force upon grief communication, as managed by avoiding the topic, displaying oversympathetic emotions, and saying "It's time to move on." These types of reactions are manifestations of the dominant narrative, and the subsequent management of grief identity can leave grieving individuals feeling disenfranchised, socially isolated, misunderstood, and invalidated. As Goodrum (2008) summarizes, the emotional burden of grief is ultimately the responsibility of both grieving individuals and those around them, who must simultaneously manage their grief and ease others' discomfort with grief in their interpersonal relationships.

\section{Potential Directions for Future Research}

Just as people and relationships have numerous idiosyncrasies and unique qualities, so too does grief following the loss of another person and relationship. Even still, Jakoby (2014) found that most people want to share their grief with others. The problem, as we emphasize in this review, is that performing one's personal experience of grief often contrasts against the dominant narrative that others hold about the "right" way to grieve.

The claim that grief is always disenfranchised is admittedly controversial. Yet, the idea gives rise to several potentially fruitful research pursuits that could hold both theoretical and practical value. For one, future research could further explore the intersection between grief performances and the dominant narrative to uncover further details about the nature of disenfranchisement in grief. The approach we take here suggests that disenfranchisement is primarily located in the interactions between bereaved and non-grieving counterparts, but further research could help illuminate the features of interactions that both represent the dominant narrative, and increase or decrease a sense of disenfranchisement.
The development and management of grief-related identity is a second area for research. If grief indeed adds aspects to one's identity, then the experience of grief would offer a location for researchers to uncover ways that this and other identities get negotiated over time. Disenfranchised identity and grief are not likely dichotomous, but probably scaled according to various factors that have yet to be determined. A related possibility is that the manifestations of grief identity vary according to the intensity of grief identity. Thus, examining the connection between the intensity of one's identification with grief, the experience of disenfranchisement, and the actual communicative manifestations of grief could be theoretically fruitful. Given the dominant narrative, the negotiation of grief identity is unlikely to be a smooth one. Nevertheless, understanding the ways it is navigated could yield important insights into how exactly people competently perform grief in ways that allow them to grow into their new identities within their ongoing relationships.

Third, future studies should examine how other sources of disenfranchisement might influence adaptation to a changed identity in the process of grief. One possibility, for example, would be to examine how the co-occurrence of multiple sources of disenfranchised identity (e.g., invisible physical or psychological ailments) interrelate with the experience of grief to influence interactions within it. The potential blending of identities and grief experiences would imply a complicated set of messages that individuals must coordinate to successfully negotiate their relationships with others, which will also likely change in the face of loss of a significant person in one's life.

While rather extensive research has been done addressing contexts of stigmatized death and disenfranchised grief, fewer studies have addressed disenfranchisement of nonstigmatized death. Contrary to the traditional theory of disenfranchised grief, disenfranchisement still occurs for individuals whose loved ones died "good" (non-stigmatized) deaths, though perhaps to a different degree compared to stigmatized deaths. Even so, the experiences of these individuals and families have been generally overlooked, and could offer deeper insight into the experience of grief. Examining the type or timing of loss in correlation with types of disenfranchisement could yield deep insight into the performance and experience of grief in interpersonal communication. Further, future research could explore the role of disenfranchisement in grief outcomes, such as adjustment and social functioning (e.g., Bonanno et al., 2002; Bonanno, 
Boerner, \& Wortman, 2008). For example, further inquiry may highlight how disenfranchising communication may correlate with cases of depression and chronic grieving after loss.

Certainly, culture plays an essential role in the experience of stigmatized and non-stigmatized deaths, messages used to express grief, and beliefs about death and dying. Scholars have explored the means by which various cultures practice grief and death, but relatively few have explored the communicative manifestations of those discourses and, further, how such discourses may disenfranchise the experiences of many members of those communities. As previously mentioned, the existence of disenfranchised grief suggests that every society has a dominant narrative of grief (Doka, 2002). Both dominant and individual narratives will certainly vary by region and culture, and one could expect that cultures might also vary by the degree to which dominant and individual narratives are discrepant, acknowledged, or validated. One possibility, for example, is that cultures with strong values toward individualism allow somewhat more liberty toward others' unique expressions of grief, and thus make the discrepancy between the dominant and individual narratives less distressing than the discrepancy might be in highly collectivistic cultures.

Some languages might also have terms (or alternatively, be missing terms) to describe death and grief that either carry or suppress various connotations about death and grief. As previously discussed in this essay, the presence or absence of terms to describe grief in a given language can alter societal expectations for how grief "should" be performed. In the English language, for example, someone whose spouse has died is called a "widow" or "widower." However, as Belkin (2010) points out, no similar word exists in English to describe a parent whose child has died. Belkin suggests that perhaps the best word to describe a parent whose child has died could be the Sanskirt term "vilomah," meaning "against the natural order." The interpretation of the term carries various connotations about the role and expectations around it, while also seeming to fully capture the essence of the loss and the trauma surrounding it. Further research on how the presence or absence of labels can influence one's perception of (dis)enfranchisement might be both theoretically and practically fruitful.

Given the approach to grief identity taken here, the use of narrative methodology would be appropriate. Indeed, Willer et al. (2018) and Funk et al. (2018) offer two studies analyzing grief through storytelling methods. However, other methodologies can also yield valuable insights into grief experiences and expressions. For example, Phipps (2018) offers a narrative account through auto-ethnography, a method that could illuminate some aspects of grief identity that might otherwise be invisible through more traditional social scientific methods by allowing a connection between extensive self-reflection and larger cultural meanings around grief. Performative methods could likewise facilitate a connection the knower and the known and further highlight aspects of grief identity that are otherwise difficult to see in light of a dominant narrative's presence. Regardless of the strengths and weaknesses of specific methodologies, the nuanced, and often idiosyncratic ways in which grief identity can play out justify the use of methods that transcend traditional social scientific methodologies. These are the types of methods that draw upon the nuances of the experience themselves to build knowledge from the inside out.

\section{Conclusion}

Grief and death are experiences that every human will inevitably encounter. Grief suddenly and permanently becomes a part of one's identity, making them a member of a club nobody ever wants to join. Unfortunately, when grief experiences are confined to a dominant narrative, the experience is difficult to communicate, and potentially silences the very voice of one's identity. To break this silence, grief, as a part of one's identity, must be acknowledged and validated through the process of communication.

The communicative responses of non-bereaved counterparts further complicate the performances of grieving individuals. However, that does not make communicating about grief an impossible task. In fact, some interactions may leave bereaved individuals' grief enfranchised, acknowledged, and validated. For example, in describing a loss in an autoetnography, Walter (1996) wrote:

What had healing power was being able to talk honestly about Corina with others who knew her. Corina valued direct and honest communication; fortunately, her friends reflected this virtue, so we could talk with equal love about her strengths and her failings, the joys and the frustrations of knowing her. (p. 13)

In a separate study of grief expressions in online contexts (Barney, 2019b), one participant wrote that: 
When people show a genuine interest when I share a memory, when those who knew Nathan or Derek get excited to talk and share memories, when people share a similar story of feeling their loved one around in their present day...I feel so much safer. (p. 13)

Newer technology also affords additionl discourses in the public sphere that also attempt to dismantle the dominant narrative of grief by providing vocabularies for nonlinear grieving. Podcasts, TED Talks, and online forums are a few of many examples of broadening discourses around bereavement. In a publically available TED Talk, for example, McInerny (2018b) stated that, "people are experiencing deeply formative and traumatic losses every day...these are the experiences that mark us and make us just as much as the joyful ones, and just as permanently." Thus, while disenfranchisement of grief may be perpetual, it does not have to be inevitable. Communicating openly about a multitude of grief experiences and thus challenging the notion that there is one "normal" way of grieving may be a good first step toward changing the dominant narrative of grief in a productive and inclusive way. Counter-discourses to the dominant narrative of grieving could better equip mental health profes- sionals to support clients, help organizations to better support bereaved employees, and make the social world more aware of the myth that grief is linear and transitory.

When the social networks of individuals affected by grief fail to properly emphasize and provide adequate social support, they deny themselves the opportunity to learn, overcome communication barriers, redefine the dominant narrative of grief, and, most importantly, help a grieving person feel less alone. When bereaved individuals swallow their own grief out of consideration for others and to follow cultural norms, they miss an opportunity to educate, overcome communication barriers, redefine the dominant narrative of grief, and yield the benefits of social support. More broadly, they structure disenfranchised grief into their identity.

Failing to acknowledge grief as a lifelong experience establishes barriers in how grief is communicated both interpersonally and societally. Perhaps a broader understanding may change the experience of grief for the better, allowing practitioners, counselors, and people alike to provide stronger support for bereaved individuals, and, in turn, reshape the dominant narrative of grief.

\section{Acknowledgements}

The authors thank Keith Anderson, Ph.D. for feedback on previous versions of this review. 


\section{References}

Archer, J. (2008). Theories of grief: Past, present, and future perspectives. In M. S. Stroebe, R. O. Hansson, H. Schut, and W. Stroebe (Eds.), Handbook of Bereavement Research and Practice: Advances in Theory and Intervention (pp. 45-65). Washington, DC: American Psychological Association. doi: 10.1037/14498-003

Baddeley, J., \& Singer, J. A. (2010). A loss in the family: Silence, memory, and narrative identity after bereavement. Memory, 18(2), 198-207. doi: 10.1080/09658210903143858

Barney, K. A. (2019a). Imagined interactions in continuing bonds: An investigation of letter writing. Unpublished manuscript, Department of Communication Studies, University of Montana, Missoula, MT.

Barney, K. A. (2019b). The Role of SNS in Communicating with Surviving Others About Continuing Bonds. Unpublished manuscript, Department of Communication Studies, University of Montana, Missoula, MT.

Basinger, E. D., Wehrman, E. C., \& McAninch, K. G. (2016). Grief communication and privacy rules: Examining the communication of individuals bereaved by the death of a family member. Journal of Family Communication, 16(4), 285-302. doi: $10.1080 / 15267431.2016 .1182534$

Belkin, L. (2010, June 8). Describing Grief. Retrieved from https://parenting.blogs.nytimes.com/2010/06/08/describing-grief/.

Bonanno, G. A. (2001). Grief and emotion: A social-functional perspective. In M. S. Stroebe, R. O. Hansson, W. Stroebe, and H. Schut (Eds.), Handbook of Bereavement Research: Consequences, Coping, and Care, pp. 493-515.

Bonanno, G. A., Boerner, K., \& Wortman, C. (2008). Trajectories of grieving. In In M. S. Stroebe, R. O. Hansson, W. Stroebe, H. Schut, and W. Stroebe (Eds.), Handbook of Bereavement Research: Advances in Theory and Intervention, pp. 287-307.

Bonanno, G. A., Wortman, C. B., Lehman, D. R., Tweed, R. G., Haring, M., Sonnega, J., . . Nesse, R. M. (2002). Resilience to loss and chronic grief: A prospective study from preloss to 18-months postloss. Journal of Personality and Social Psychology, 83(5), 1150-1164. doi: 10.1037/0022-3514.83.5.1150

Bonnette, S. \& Broom, A. (2011). On grief, father, and the male role in men's accounts of stillbirth. Journal of Sociology, 48(3), 248-265. doi: 10.1177/1440783311413485

Bowlby, J. (1980). Attachment and Loss. Vol. 3: Loss, Sadness and Depression. New York, NY: Basic Books.

Buglass, E. (2010). Grief and bereavement theories. Nursing Standard, 24, 44-47. doi: 10.7748/ns2010.06.24.41.44.c7834

Burke, P. J. (1980). The Self: Measurement requirements from an interactionist perspective. Social Psychology Quarterly, 43(1), 18-29. doi:10.2307/3033745

Cohen, H. \& Samp, J. A. (2018). Grief communication: Exploring disclosure and avoidance across the developmental spectrum. Western Journal of Communication, 82(2), 238-257. doi: 10.1080/10570314.2017.1326622

Corr, C. A. (1998). Enhancing the concept of disenfranchised grief. OMEGA - Journal of Death and Dying, 38(1), 1-20. doi: 10.2190/LD26-42A6-1EAV-3MDN

Creighton, G., Oliffe, J. L., Butterwick, S., \& Saewyc, E. (2013). After the death of a friend: Young men's grief and masculine identities. Social Science and Medicine, 84, 35-43. doi: 10.1016/j.socscimed.2013.02.022

Dennis, M. R., \& Kunkel, A. (2012). Relationship after loss: Communication in the new grief paradigm. In O. Gillath, G. Adams, \& A. Kunkel (Eds.), Relationship science: Integrating evolutionary, neuroscience, and sociocultural approaches (pp. 199-218). Washington, D.C.: American Psychological Association.

Dillard, J. P. (1990). A goal-driven model of interpersonal influence. In J. P. Dillard (Ed.), Seeking compliance: The production of interpersonal influence messages (pp. 41-56). Scottsdale, AZ: Gorsuch Scarisbrick.

Doka, K. J. (2002). Disenfranchised grief. In K. J. Doka (Ed.), Living with grief: loss in later life (pp. 159-168). Washington, D.C.: The Hospice Foundation of America.

Doka, K. J. (2009). Disenfranchised grief. Bereavement Care, 18(3), 37-39. doi: 10.1080/026826299086657467

Doka, K. J. \& Martin, T. (1998). Masculine responses to loss: Clinical implications. Journal of Family Studies, 4(2), 142-158. doi: $10.5172 /$ jfs.4.2.143

Feigelman, W., Jordan, J. R., \& Gorman, B. S. (2011). Parental grief after a child's drug death compared to other death causes: Investigating a greatly neglected bereavement population. Omega, 63(4), 291-316. doi: 10.2190/OM.63.4.a 
Fischer, A. H., \& Manstead, A. S. R. (2016). Social functions of emotion and emotion regulation. In M. Lewis, J. Haviland, \& L. Feldman Barrett (Eds.), Handbook of Emotion (4th ed., pp. 456-469). New York, NY: Guilford.

Freud, S. (1957). Mourning and melancholia. In J. Strachey (Ed.), The standard edition of the complete psychological works of Sigmund Freud (Vol. 14, 152-170). London, U.K.: Hogarth Press. (Original work published 1917)

Funk, A. M., Jenkins, S., Astroth, K. S., Braswell, G., \& Kerber, C. (2018). A narrative analysis of sibling grief. Journal of Loss and Trauma, 23(1), 1-14. doi: 10.1080/15325024.2017.1396281

Goodrum, S. (2008). When the management of grief becomes everyday life: The aftermath of murder. Symbolic Interaction, 31(4), 422-442. doi:10.1525/si.2008.31.4.422

Goldie, P. (2011). Grief: A narrative account. Ratio, 24(2), 119-137. doi: 10.1111/j.1467-9329.2011.00488.x

Granek, L. (2010). Grief as pathology: The evolution of grief theory in psychology from Freud to the present. History of Psychology, 13(1), 46-73. doi: 10.1037/a0016991

Green, L. \& Grant, V. (2008). 'Gagged grief and beleaguered bereavements?' An analysis of multidisciplinary theory and research relating to same sex partnership bereavement. Sexualities, 11(3), 275-300. doi: 10.1177/1363460708089421

Greenberg, D. L. \& Rubin, D. C. (2003). The neuropsychology of autobiographical memory. Cortex, 39(4), 687-728. doi: $10.1016 / \mathrm{S} 0010-9452(08) 70860-8$

Gündel, H., O'Connor, M., Littrell, L., Fort, C., \& Lane, D. R. (2003). Functional neuroanatomy of grief: An fMRI study. American Journal of Psychiatry, 160(11), 1946-1953. doi: 10.1176/appi.ajp.160.11.1946

House, J. (1981). Work stress and social support (Addison-Wesley series on occupational stress). Reading: Addison-Wesley Pub. Ironside, V. (1997). "You'll get over it": The rage of bereavement. London: Penguin UK.

Jakoby, N. R. (2014) Talking about grief: Conversational partners sought by bereaved people. Bereavement Care, 33(1), 13-18. doi: 10.1080/02682621.2014.902611

Johannsen, R. (1974). The functions of silence: A plea for communication research. Western Speech, 38, 25-35. doi: $10.1080 / 10570317409373806$

Kauffman, J. (2002). The psychology of disenfranchised grief: Liberation, shame and self-disenfranchisement. In K. J. Doka (Ed.), Disenfranchised grief: New directions, challenges, and strategies. Champaign, IL: Research Press.

Klass, D., Silverman, P. R., and Nickman, S. L. (Eds.). (1996). Continuing bonds: New understandings of grief. Philadelphia, PA, US: Taylor \& Francis.

Koenig Kellas, J. (2018). Communicated narrative sense-making theory. In D. O. Braithwaite, E. A. Suter, \& K. Floyd (Eds.), Engaging theories in family communication (2nd ed.), pp. 62-74.

Kofod, E. H. (2017). From morality to pathology: A brief historization of contemporary Western grief practices and understandings. Nordic Psychology, 69(1), 47-60. doi: 10.1080/19012276.2016.1267914

Kübler-Ross, E., \& Kessler, D. (2005). On grief and grieving: Finding the meaning of grief through the five stages of loss. New York, NY: Scribner.

Kusmaul, N. \& Anderson, K. (2018). Applying a trauma-informed perspective to loss and change in the lives of older adults. Social Work in Health Care, 57(5), 355-375. doi: 10.1080/00981389.2018.1447531

Lang, A., Fleiszer, A., Duhamel, F., Sword, W., Gilbert, K. R., Corsini-Munt, S. (2011). Perinatal loss and parental grief: The challenge of ambiguity and the disenfranchised grief. Omega, 63(2), 183-196. doi: 10.2190/OM.63.2.e

Lazarus, R. S. (1991). Emotion and Adaptation. Oxford, UK: Oxford University Press

Lopes, P. N., Salovey, P., Côté, S., \& Beers, M. (2005). Emotion regulation abilities and the quality of social interaction. Emotion, 5, 113-118. doi: 10.1037/1528-3542.5.1.113

McAdams, D. P. (2001). The psychology of life stories. Review of General Psychology, 5, 100-122. doi: 10.1037/1089-2680.5.2.100

McInerny, N. (Host). (2018a, November 19). Terrible, thanks for asking [Audio podcast]. Retrieved from https://itunes.apple. com/us/podcast/terrible-thanks-for-asking/id1126119288? $\mathrm{mt}=2$

McInerny, N. (2018b, June). We don't "move on" from grief, we move forward with it [Video file]. Retrieved from https://www. ted.com/talks/nora_mcinerny_we_don_t_move_on_from_grief_we_move_forward_with_it 
Moran, L. S. (2016). Men in mourning: Depiction of masculinity in young and older widowers in contemporary film. Men and Masculinities, 19(1), 85-104. doi: 10.1177/1097184X15588591

Neimeyer, R. A. (2014). The changing face of grief: Contemporary directions in theory, research, and practice. Progress in Palliative Care, 22(3), 125-130. doi: 10.1179/1743291X13Y.0000000075

Neimeyer, R. A., Klass, D., \& Dennis, M. R., (2014). Toward a social constructionist account of grief: Loss and the narration of meaning. Death Studies, 38(8), 485-498. doi: 10.1080/07481187.2014.913454

Park, C. L. (2010). Making sense of the meaning literature: An integrative review of meaning making and its effects on adjustment to stressful life events. Psychology Bulletin, 136(2), 257-301. doi: 10.1037/a0018301

Phipps, C. B. (2018). Metamorphosis: An autoethnographic journey through loss, grief, and perceived identity changes. Journal of Loss and Trauma. doi: 10.1080/15325024.2018.1475138

Pitman, A. L., Stevenson, F., Osborn, D. P. J., \& King, M. B. (2018). The stigma associated with bereavement by suicide and other sudden deaths: A qualitative interview study. Social Science \& Medicine, 198, 121-129. doi: 10.1016/j.socscimed.2017.12.035

Rosenblatt, P. C. (1996). Grief that does not end. In D. Klass, P. R. Silverman, and S. L. Nickman, Continuing bonds: New understandings of grief, pp. 45-58.

Sharoff, K. (2004). Coping skills therapy for managing chronic and terminal illness. New York, NY: Springer Publishing Company.

Spaten, O. M., Brialsen, M. N., \& Langdridge, D., (2011). Men's grief, meaning and growth: A phenomenological investigation into the experience of loss. Indo-Pacific Journal of Phenomenology, 11(2), 1-15. doi:10.2989/IPJP.2011.11.2.4.1163

Stroebe, M. (2010). From mourning and melancholia to bereavement and biography: An assessment of Walter's new model of grief. Mortality, 2(3), 255-262. doi:10.1080/714892787

Stroebe, M., \& Schut, H. (1999). The dual process model of coping with bereavement: Rationale and description. Death Studies, Vol. 23, pp. 197-224. doi: 10.1080/074811899201046

Stryker, S. (1980). Symbolic interactionism: a social structural version. Caldwell, NJ: Blackburn Press.

Thompson, N., Allan, J., Carverhill, P. A., Cox, G. R., Davies, B., Doka, K., .. Wittkowski, J. (2016). The case for a sociology of dying, death, and bereavement. Death Studies, 40(3), 172-181. doi: 10/1080/07481187.2015.1109377

Valentine, C., Bauld, L., \& Walter, T. (2016). Bereavement following substance misuse: A disenfranchised grief. Journal of Death and Dying, 72(4), 283-301. doi: 10.1177/0030222815625174

van der Geest, S. (2004). Good and bad death: Introduction. Social Science \& Medicine, 58, 883-885. doi: 10.1016/j.socscimed.2003.10.034

Walter, T. (1996). A new model of grief: Bereavement and biography. Mortality, 1(1), 7-25. doi:10.10980/713685822

Walter, T., Ford, A., Templeton, L. Valentine, C., \& Velleman, R. (2017). Compassion or stigma? How adults bereaved by alcohol or drugs experience services. Health and Social Care in the Community, 25(6), 1714-1721. doi: 10.1111/hsc.12273

Willer, E. K., Droser, V. A., Hoyt, K. D., Hunniecutt, J., Krebs, E., Johnson, J. A., \& Castaneda, N. (2018). A visual narrative analysis of children's baby loss remembrance drawings. Journal of Family Communication, 18(2), 153-169. doi: $10.1080 / 15267431.2018 .1428608$ 


\section{Copyrights and Repositories}

\section{(\$) (1)}

This work is licensed under the Creative Commons Attribution-NonCommercial-3.0 Unported License.

This license allows you to download this article titled "Death-Related Grief and Disenfranchised Identity: A Communication Approach" and share it with others as long as you credit the author and the journal. You cannot use it commercially without the written permission of the author and the journal (Review of Communication Research).

\section{Attribution}

You must attribute the work to the author and mention the journal with a full citation, whenever a fragment or the full text of this paper is being copied, distributed or made accessible publicly by any means.

\section{Commercial use}

The licensor permits others to copy, distribute, display, and perform the work for non-commercial purposes only, unless you get the written permission of the author and the journal.

The above rules are crucial and bound to the general license agreement that you can read at:

http://creativecommons.org/licenses/by-nc/3.0/

\section{Corresponding author}

Kendyl A. Barney

University of Montana

Department of Communication Studies

32 Campus Drive, Missoula, MT 59801

kendyl.barney@umontana.edu

\section{Attached is a list of permanent repositories where you can find the articles published by RCR:}

Academia.edu@ @ttp://independent.academia.edu/ReviewofCommunicationResearch

Internet Archive @ http://archive.org (collection "community texts")

Social Science Open Access Repository, SSOAR @ http://www.ssoar.info/en/home.html 